\title{
Absorption of ${ }^{51} \mathrm{Cr}$ EDTA across the human nasal airway barriers in the presence of topical histamine
}

\author{
Lennart Greiff, Per Wollmer, Ulf Pipkorn, ` Carl G A Persson
}

\begin{abstract}
Whether histamine, a mediator that causes exudation, affects the airway absorption of luminal solutes has been examined in a study of eight healthy volunteers. Fluid containing the absorption tracer chromium-51 labelled EDTA was instilled into one nasal cavity for 15 minutes, with a nasal pool-device (total volume $14 \mathrm{ml}$ ). The airway absorption of ${ }^{51} \mathrm{Cr}$ EDTA determined by urinary recovery of radioactivity corresponded to 0.095 (SE 0.023 ) $\mathrm{ml}$ of the instillate in the absence of histamine. When histamine was added to the nasal instillate at a concentration of $2.0 \mathrm{mg} / \mathrm{ml}$, which is known to produce substantial exudation of plasma into the airway lumen, the absorption of ${ }^{51} \mathrm{Cr}$ EDTA was unchanged $(0.093(0.025) \mathrm{ml}$ of the instillate). Separate experiments excluded the possibility that any swallowed portion of ${ }^{51} \mathrm{Cr}$ EDTA could have contributed significantly to the amount absorbed. The present data agree with previous observations in guinea pig tracheobronchial airways, where histamine and other exudative agents did not increase the mucosal absorption of solutes from the airway lumen. These data suggest that the potent protein systems of blood plasma can transverse the endothelialepithelial linings and operate on the surface of the airway mucosa without compromising its integrity as a barrier to luminal material.
\end{abstract}

It has been suggested that increased absorption of inhaled material may occur in asthmatic and rhinitic airways and that such an abnormality of the mucosa might contribute to the hyperresponsiveness seen in these diseases. ${ }^{1-3}$ The increased mucosal permeability is usually assumed to be bidirectional $^{23}$ and thus the presence of plasma proteins in the airway lumen has been taken as support for an increased airway absorption capacity. ${ }^{23}$

The epithelial lining is asymmetrical in many respects and recent findings in guinea pig airways suggest that an increased outward (exudative) permeability may not be associated with an increased inward (absorptive) permeability. ${ }^{46}$ If the same is true in man plasma exudation might occur in asthmatic and rhinitic airways without there being any increase in absorption. Some clinical data suggest that mucosal absorption may be unchanged (or reduced) in patients with rhinitis and asthma. ${ }^{7-9}$

The application of histamine $(1.0 \mathrm{mg})$ to the nasal mucosa produces substantial and repeatable plasma exudation. ${ }^{10}$ Greiff et al, ${ }^{11}$ using a nasal pool-device, found a concentration-response relationship for exudation of albumin in response to histamine on the human nasal mucosa, and the response to a high concentration of histamine $(2.0 \mathrm{mg} / \mathrm{ml})$ was repeatable.

We have now tried to determine whether a high concentration of histamine $(2.0 \mathrm{mg} / \mathrm{ml}$ in the nasal pool fluid) is associated with any change in the rate of absorption of chromium51 labelled EDTA (MW 372) across the exposed airway mucosa. Histamine and ${ }^{51} \mathrm{Cr}$ EDTA were applied concomitantly to the nasal airway mucosa, a nasal pool device being used to ensure that a controlled concentration of histamine and the absorption tracer were brought into contact with the same large area of nasal mucosa (exudative indices were not analysed-they generally correlate well with the symptoms that occurred transiently in the present study ${ }^{11}$ ).

\section{Methods}

\section{SUBJECTS}

Nasal absorption of ${ }^{51} \mathrm{Cr}$ EDTA was examined in eight healthy male non-smokers aged 22-28 years. The subjects had no known airway disease and the nasal mucosa was normal on inspection. Gastrointestinal absorption of ${ }^{51} \mathrm{Cr}$ EDTA was examined in a separate group of six healthy male non-smokers aged 25-38 years. No drugs were allowed during the course of the study. Informed consent was obtained from the subjects and the study was approved by the ethics committee of the University Hospital of Lund.

THE NASAL POOL TECHNIQUE

The nasal pool-device is a compressible plastic container with a nasal adaptor. ${ }^{11}$ The adaptor is inserted into one nostril by the subject himself, sitting with his head flexed forward $60^{\circ}$. The container is compressed just to fill the unilateral nasal cavity. After 15 minutes the pressure on the nasal pool-device is released and the instilled nasal pool fluid is returned into the container. The exposed nasal mucosa is thus gently lavaged. Two additional quick lavages with isotonic saline are then carried out promptly. At the first visit the nasal pool fluid contained ${ }^{51} \mathrm{Cr}$ EDTA 
(about $5 \mathrm{MBq}$ ), albumin $(50 \mathrm{mg} / \mathrm{ml})$, and isotonic saline (total volume $14 \mathrm{ml}$ ). At the second visit, 10 days later, histamine $(2.0 \mathrm{mg}$ $\mathrm{ml}$ ) was added to the nasal pool fluid, which otherwise had the same composition as on the first day.

\section{NASAL SYMPTOMS}

Nasal blockage was scored $(0=$ none, $1=$ mild, 2 = moderate, 3 = severe blockage) by the subjects one minute after the completion of the nasal instillation procedure.

DETERMINATION OF NASAL ABSORPTION OF ${ }^{51} \mathrm{Cr}$ EDTA

The nasal absorption of ${ }^{51} \mathrm{Cr}$ EDTA during the 15 minutes of exposure was determined by sampling the urine produced over the 24 hours after the instillation procedure. Three samples (each $3.0 \mathrm{ml}$ ) were taken from the pooled 24 hour urine and the activity was counted in a well counter for 1000 seconds. Two samples (each $3.0 \mathrm{ml}$ ) of a standard solution (prepared by diluting samples of $0 \cdot 1$ $\mathrm{ml}$ of the nasal pool solution in $100 \mathrm{ml}$ saline) were also counted. The amount of ${ }^{51} \mathrm{Cr}$ EDTA absorbed was calculated from the urine volumes and the count rates of the urine samples and the standard solutions. The amount was expressed as the equivalent volume of the nasal instillate that would have contained the ${ }^{51} \mathrm{Cr}$ EDTA absorbed.

\section{DETERMINATION OF NASAL RETAINMENT AND} ORAL ABSORPTION OF ${ }^{51} \mathrm{Cr}$ EDTA

Immediately after the nasal instillation procedure the count rates of ${ }^{51} \mathrm{Cr}$ over the nose and upper abdomen were determined for two minutes with a gamma camera. In a separate experiment the entire nasal pool fluid $(14 \mathrm{ml}$, with ${ }^{51} \mathrm{Cr}$ EDTA but without histamine) was administered orally.

\section{ANALYSIS}

Data are presented as means with standard errors in parentheses. The Student's $t$ test for paired observations was used for statistical analysis. A p value less than 0.05 was considered significant (two tailed test).

\section{Results}

Histamine caused nasal blockage (score 3 ) in all subjects.

The baseline absorption of ${ }^{51} \mathrm{Cr}$ EDTA during the 15 minutes of the nasal instillation without histamine was equivalent to 0.095 $(0.023) \mathrm{ml}$ instillate. The addition of histamine to the instillate did not alter the absorption of ${ }^{51} \mathrm{Cr}$ EDTA $(0.093(0.025) \mathrm{ml} ; \mathrm{p}>0.05)$. The 24 hour urine volumes did not differ, being 1240 (136) $\mathrm{ml}$ in control subjects and $1097(84) \mathrm{ml}$ in those exposed to histamine.

After completion of instillation and withdrawal of the nasal instillate there was no detectable activity of ${ }^{51} \mathrm{Cr}$ in the nasal area or over the upper abdomen. Oral administration of the total nasal pool dose of ${ }^{51} \mathrm{Cr}$ EDTA caused only marginal 24 hour absorption of this compound $(0.085(0.021) \mathrm{ml})$.

\section{Discussion}

This study shows that the absorption of ${ }^{51} \mathrm{Cr}$ EDTA across the human nasal mucosa is not affected by histamine. This agrees with data obtained in guinea pig tracheobronchial airways, where different exudative stimuli, including histamine, did not affect the absorption rate of luminal solutes. ${ }^{+6}$ These findings may be important for our understanding of the role of plasma exudation in airway defence and in the pathogenesis of airway disease. Plasma exudation in the airways is not mentioned in current publications on respiratory defence. ${ }^{12}{ }^{13}$ Plasma exudation into the airway lumen is generally thought to occur only in airways where the epithelial lining has been severely disrupted. ${ }^{13}$ If, however, the potent protein systems in plasma can traverse the mucosa and operate on the airway surface without compromising the integrity of the epithelial lining as a barrier to solutes from the lumen plasma exudation has to be ranked as a first line respiratory defence mechanism. ${ }^{14} \mathrm{~A}$ further inference is that plasma exudation into the lumen can occur in airway disease, ${ }^{15}$ even when there is no epithelial disruption and when absorption of material from the lumen remains normal.

Plasma exudation starts promptly after topical application of histamine and the response peaks within 10 minutes. ${ }^{4111}$ Probably therefore plasma was being exuded throughout the 15 minutes during which absorption of ${ }^{51} \mathrm{Cr}$ EDTA was being examined. We cannot exclude the possibility that histamine induced submucosal swelling (the blockage in this study) could have affected the absorption of ${ }^{51} \mathrm{Cr}$ EDTA and the exudation of albumin. We think this is unlikely to be a major influence because the present data agree with findings in guinea pig airways, where exudation occurred without change in absorption ${ }^{56}$ and without producing detectable oedema. ${ }^{15}$ In addition, in human nasal experiments a vasoconstrictor drug reduced the histamine induced nasal blockage but not the exudation of albumin. ${ }^{16}$

Acute mediator induced plasma exudation appears to be largely an unfiltered flow of different sized and different charged plasma solutes across the vascular endothelial wall and the mucosal epithelial lining. ${ }^{417}$ Thus the exudation of plasma in response to an inflammatory stimulus represents a major increase in the outward permeability of the airway barriers. Inward absorption permeability, however, may not increase, as suggested by previous studies in animals ${ }^{4-6}$ and the present results. Possibly a hydrostatic, pressure regulated, valve like mechanism may account for epithelial crossing of the plasma exudate that leaves absorption unaffected. This is suggested by animal studies in vivo and by in vitro observations that indicate that the epithelial lining has a normal appearance once the exudation process is complete. ${ }^{1418-20}$

${ }^{51} \mathrm{Cr}$ EDTA (MW 372) is a water soluble compound similar in size and character to technetium-99m labelled diethylenetriamine penta-acetate (DTPA) (MW 492), which has frequently been used to study bronchoalveolar absorption barriers in health and disease..$^{2122}$ 
We selected ${ }^{51} \mathrm{Cr}$ EDTA because it is stable, renal elimination can be measured after absorption, ${ }^{23}$ and any swallowed ${ }^{51} \mathrm{Cr}$ EDTA would not affect the nasal absorption results appreciably. ${ }^{24}$ We confirmed previous findings ${ }^{24}$ that oral ingestion of ${ }^{51} \mathrm{Cr}$ EDTA results in a 24 hour urinary excretion of radioactivity corresponding to only about $0.5 \%$ of the ingested dose.

Inhaled histamine has been shown to increase pulmonary clearance of ${ }^{99 \mathrm{~m}} \mathrm{Tc}$ DTPA. ${ }^{25}{ }^{26}$ It is difficult to examine the human tracheobronchial barrier functions, however, with an acceptable specificity. The distribution of tracers and provocative agents cannot be controlled as closely as in nasal airways. It is also difficult to make a clear distinction between bronchial and alveolar barriers. Recent animal studies and a series of nasal experiments in man suggest that the barrier functions of nasal and tracheobronchial airways have important similarities. ${ }^{1427}$ Thus the present data suggesting that exudative and absorptive permeabilities are separate are also likely to be applicable to the human tracheobronchial airways.

The present data, together with our previous findings with histamine, suggest that plasma exudation into the airway lumen is not necessarily associated with a change in the absorptive ability of the airway mucosa. A unidirectional increase in outward permeability is a potentially important respiratory defence mechanism but may also play a part in airway disease. The human nasal mucosa is readily accessible for quantitative and airway specific experiments and might prove an important site for further studies of the relation between inward and outward permeabilities of the airway mucosa.

The study was supported by grants from the Swedish Medical Research Council (projects 8308 and 2872).

1 Leskowitz S, Salvaggio JE, Schwartz HJ. An hypothesis for the development of atopic allergy in man. Clin Allergy 1972;2:237-42.

2 Boucher RC, Ranga V, Pare PD, Inoue S, Moroz LA, Hogg JC. Effect of histamine and methacholine on guinea pig tracheal permeability to HRP. J Appl Physiol 1978; 45:939-48.

3 Ranga V, Powers MA, Padilla M, Strope GL, Fowler L, Kleinerman J. Effect of allergic bronchoconstriction on airways epithelial permeability to large polar solutes in the guinea pig. Am Rev Respir Dis 1983;128:1065-70.

4 Erjefält I, Persson CGA. Inflammatory passage of plasma macromolecules into airway wall and lumen. Pulm Pharmacol 1989;2:93-102.

5 Erjefält I, Persson CGA. Allergen, bradykinin, and cap- saicin increase outward but not inward macromolecular permeability of the tracheobronchial mucosa. Clin Exp Allergy 1991;21:217-24.

6 Greiff L, Erjefält I, Wollmer P, Pipkorn U, Persson CGA Effects of histamine, ethanol, and a detergent on exudation and absorption across guinea pig airway mucosa in vivo. Thorax (in press)

7 Cohen MB, Ecker EE, Breitbart JR, Rudolph JA. The rate of absorption of ragweed pollen material from the nose. $J$ Immunol 1930;18:419-25.

8 Elwood RK, Kennedy S, Belzberg A, Hogg JC, Pare PD. Respiratory mucosal permeability in asthma. Am Rev Respir Dis 1983;128:523-7.

9 O'Byrne PM, Dolovich M, Dirks R, Roberts RS, Newhouse MT. Lung epithelial permeability: relation to non-specific airway hyperresponsiveness. J Appl Physiol 1984;57: airway

10 Svensson C, Baumgarten CR, Pipkorn U, Alkner U, Persson CGA. Reversibility and reproducibility of histamineinduced plasma leakage of the human nasal airways. Thorax 1989;44:13-8.

11 Greiff L, Pipkorn U, Alkner U, Persson CGA. The nasal pool-device applies controlled concentrations of solutes on human nasal airway mucosa and samples its surface human nasal airway mucosa and samples its surface
exudations/secretions. Clin Exp Allergy 1990;20:253-9.

12 Bienenstock J. Mucosal immunological protection mechanisms in the airways. Eur J Respir Dis 1986;69(suppl 147):62-71.

13 Hansson LA, Brandzaeg P. The mucosal defence system. In: Steihm ER, Fulginiti VA, eds. Immunological disorders in infants and children. New York: Saunders, 1980:137-64.

14 Persson CGA, Erjefält I, Alkner U, Baumgarten C, Greiff L, Gustafsson B, et al. Plasma exudation as a first line respiratory mucosal defence. Clin Exp Allergy 1991; 21:17-24.

15 Persson CGA. Role of plasma exudation in asthmatic airways. Lancet 1986;ii:1126-9.

16 Svensson C, Persson CGA, Baumgarten CR, Alkner U, Pipkorn U. Topical alpha-adrenoceptor-stimulation may not reduce histamine-induced plasma leakage into human nasal airways. In: Svensson C, Thesis, University of Lund, 1990:89-101.

17 Alkner U, Svensson C, Andersson M, Pipkorn U, Persson CGA. Fibrinogen and albumin on the surface of allergenand histamine-exposed human nasal mucosa [abstract]. $J$ Allergy Clin Immunol 1991;87:217.

18 Persson CGA, Erjefält I, Gustafsson B. Subepithelial pressure may regulate plasma exudation across the mucosa. Int Arch Allergy Appl Immunol 1990;92:148-53.

19 Luts A, Sundler F, Erjefalt I, Persson CGA. The airway epithelial lining is intact promptly after the mucosal crossing of large amount of plasma exudate. Int Arch Allergy Appl Immunol 1990;91:385-8.

20 Gustafsson B, Persson CGA. Asymmetrical effects of increases in hydrostatic pressure on macromolecular movement across the airway mucosa. Clin Exp Allergy 1991;21:121-6.

21 Barrowcliffe MP, Jones JG. Solute permeability of the alveolar capillary barrier. Thorax 1987;42:1-10.

22 Jones JG, Minty BD, Lawler P, Hulands G, Crawley JCW, Veall $N$. Increased alveolar epithelial permeability in cigarette smokers. Lancet 1980;i:66-8.

23 Brochner-Mortensen J, Giese J, Rossing N. Renal inulin clearance versus total plasma clearance of ${ }^{51} \mathrm{Cr}$-EDTA Scand J Clin Lab Invest 1969;23:301-5.

24 Bjarnasson I, Peters TJ, Veall N. A persistent defect in intestinal permeability in coelic disease demonstrated by a ${ }_{51} \mathrm{Cr}$-labelled EDTA absorption test. Lancet 1983;i:323-5.

25 Braude S, Royston D, Coe C, Barnes PJ. Histamine increases lung permeability by an $\mathrm{H}_{2}$-receptor mechanism. Lancet 1984;ii:372-4.

26 Rees PJ, Shelton D, Chaw TB, Eiser N, Clark TJH, Maisey $\mathrm{MN}$. Effects of histamine on lung permeability in normal and asthmatic subjects. Thorax 1985;40:603-6.

27 Greiff L, Wollmer P, Erjefält I, Pipkorn U, Persson CGA. Clearance of ${ }^{99 m}$ Tc-DTPA from guinea pig nasal, tracheobronchial, and bronchoalveolar airways. Thorax 1990;45:841-5. 